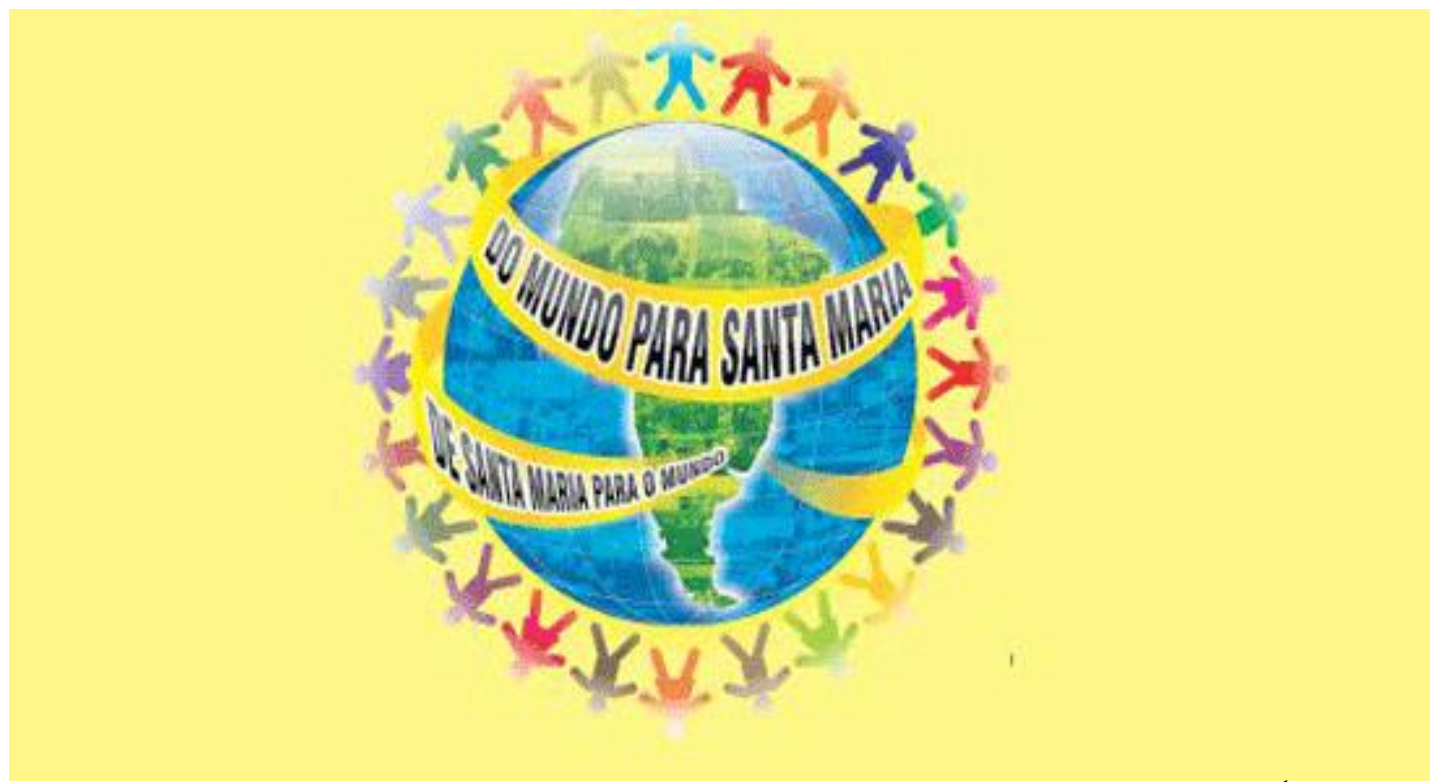

\title{
Derivas de sentido no discurso sobre a solidariedade na Feicoop ${ }^{1}$
}

Derivations of sense in the discourse about the solidarity at Feicoop

André Luís Campos Vargas ${ }^{2}$

\section{Resumo:}

Neste trabalho, buscamos compreender o funcionamento do discurso de/sobre a solidariedade na Feira do Cooperativismo de Santa Maria (Feicoop). A metodologia consiste na análise de dizeres em torno de solidariedade, mediante a noção de efeito metafórico, constituído por meio das relações de paráfrase, polissemia e metáfora. Observamos que solidariedade significa efetivamente uma prática social que implica uma outra economia e que o discurso sobre a solidariedade é indissociável do discurso de.

Palavras chave: Discurso; Solidariedade; Efeito metafórico; Cooperativismo; Globalização.

\begin{abstract}
In this work, we aim to understand the functioning of the discourse of, and about solidarity, at Feira do Cooperativismo de Santa Maria (Feicoop). The methodology consists of the analysis of sayings about solidarity based on the notion of the metaphorical effect that results from paraphrase, polysemy and metaphor. We noticed that solidarity means exclusively a social practice that implies another economy and that the discourse on solidarity is inseparable from the discourse of.
\end{abstract}

Keywords: Discourse; Solidarity; Metaphorical effect; Cooperativism; Globalization.

\footnotetext{
${ }^{1}$ Artigo resultante de Dissertação de Mestrado homônima, defendida em 01 de março de 2011, no PPGLUFSM, desenvolvida sob orientação da prof. ${ }^{a}$ Dr. Verli Fátima Petri da Silveira (PPGL-Laboratório Corpus-UFSM).

2 Mestre em Letras (PPGL-UFSM). E-mail: anndrecampos@ hotmail.com. Endereço postal: Rua Evaristo Tonin, 401, Bairro Itararé (morro). CEP 97.045 - 180. Santa Maria - RS.
} 


\section{O local e o global}

Este estudo insere-se na linha de pesquisa Língua, sujeito e história (PPGLUFSM), cujas bases teóricas abarcam a Análise de Discurso (AD) de filiação francesa, amplamente desenvolvida no Brasil, propondo uma elaboração na qual os sentidos não são mobilizados no interior do texto, mas em limites tênues nos quais os processos discursivos, por meio da construção de um dispositivo teórico, significam e ressignificam pela relação entre linguagem/memória/história.

Modernamente, o tema da globalização adquiriu uma importância política central, notadamente, pela promessa de uma economia mundializada, sem regulação social ou política, escorada por um capitalismo de internacionalização da produção, de intercâmbios e de dominância em uma sociedade regrada por mecanismos do mercado. Nosso trabalho não teve a finalidade de investigar os limites que a globalização, a mundialização e/ou o capitalismo alcançam, suscitando entusiasmo e contestação. Buscamos, de fato, refletir acerca do processo de discursivização da palavra solidariedade em circulação/funcionamento na Feira do Cooperativismo de Santa Maria, RS (Feicoop), promovida e idealizada pelo Projeto Esperança/Cooesperança, uma organização de cunho social que atua sob a coordenação da Diocese de Santa Maria. Desse modo, visamos compreender como saberes/conhecimentos, configurados como discursos de/sobre solidariedade, estruturam procedimentos de ação coletiva que postulam uma "transformação", um "outro mundo", o acontecimento de uma "outra economia", como é o caso da prática social que caracteriza e faz funcionar a Feicoop.

O corpus do trabalho é constituído por cartazes, fotos e materiais de divulgação da Feicoop, relativos às suas 15 edições (1994-2008). Essas textualidades, organizadas em torno da palavra solidariedade, são analisadas com o objetivo de observarmos como o discurso sobre funciona no que se refere às permanências, aos deslizes, aos deslocamentos, às possíveis diferenças de sentido.

Quanto ao procedimento analítico, realizamos a análise do corpus em relação aos conceitos de paráfrase, polissemia, metáfora/efeito metafórico, os quais nos permitiram observar as retomadas, as ausências, as permanências, etc. aliadas aos seus "movimentos", isto é, os deslizes, os deslocamentos, rupturas, uma vez que é em relação a uma atualidade e uma memória de dizeres que sujeitos e sentidos se significam, de modo que atentamos às condições de produção do discurso em estudo, 
visando formular, a partir da análise, um sentido possível para a solidariedade em funcionamento na Feicoop.

Levamos em conta o fato de que Orlandi $(2006,2003)$ propõe que observemos a dinâmica discursiva mediante o jogo entre dois dos processos de constituição da linguagem: a paráfrase e a polissemia. De acordo com ela, a paráfrase é considerada, na Linguística, como a matriz do sentido, uma vez que não há sentido sem repetição, sem sustentação no saber discursivo. Ela é, assim, o retorno a um mesmo espaço dizível (memória) que, todavia convive em tensão com a polissemia que, por sua vez, é considerada como a fonte da linguagem. A polissemia aponta para possibilidades de ruptura, para diferentes efeitos de sentido em relação a um mesmo objeto simbólico; é a própria condição de existência dos discursos, uma vez que, se os sentidos e os sujeitos não fossem múltiplos não haveria necessidade do dizer. Esses dois processos, paráfrase e polissemia, são igualmente atuantes e determinantes para o funcionamento da linguagem, desse modo, é difícil estabelecer limites precisos entre o mesmo (paráfrase) e o diferente (polissemia).

\section{Uma palavra por outra e o efeito resultante}

O efeito metafórico é “o fenômeno semântico produzido por uma substituição contextual, para lembrar que esse 'deslizamento de sentido' entre x e y é constitutivo do ‘sentido' designado por x e y” (PÊCHEUX, 1997, p. 96) 33 e, mais, é lugar da ideologia, da interpretação e da historicidade. O processo de produção de sentidos está, portanto, sujeito ao deslize, uma vez que sempre há um "outro" possível que o constitui; tanto o diferente como o mesmo se formulam mediante processos históricos, são afetados pelo efeito metafórico.

O que queremos sublinhar remete substancialmente à tensão entre o mesmo e o diferente, uma vez que é o mesmo da paráfrase, que é uma repetição que joga com equívoco e que, portanto, está sujeita ao diferente, que desencadeia de um efeito metafórico. A fim de ilustrarmos como trabalhamos com esses conceitos no processo analítico, com base em Orlandi (2003), elaboramos a seguinte representação:

\footnotetext{
${ }^{3}$ Grifos do autor.
} 


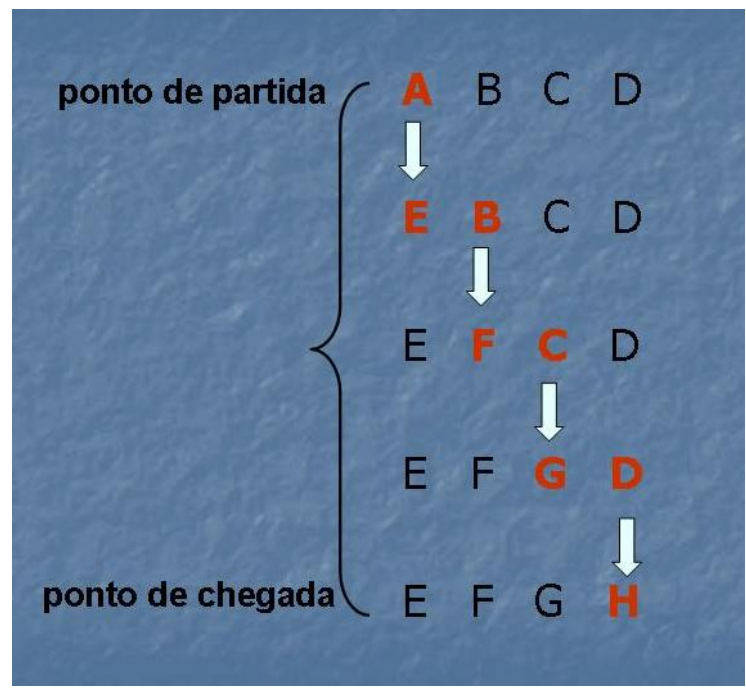

Ilustração 1 - Efeito metafórico

Adaptado de Orlandi (2003, p. 79).

Como se observa na ilustração 1 , o ponto de partida difere muito do sentido que se tem no ponto de chegada, em face dos deslizamentos de sentidos, ou seja, dos efeitos metafóricos que se efetuaram em relação contígua. Entretanto, como sublinha Orlandi (2003), a diferença entre esses pontos é sustentada em um mesmo ponto que desliza de próximo em próximo, acentuando o fato de que a diferença se dá na/pela historicidade, de que há o mesmo na diferença.

Para visualizarmos as permanências, as repetições, assim como os possíveis deslocamentos na discursivização de solidariedade na Feicoop, elaboramos um quadro cronológico com os títulos dos 15 cartazes analisados e os enunciados que aparecem em destaque.

Em realce amarelo estão os dizeres ligados à "solidariedade" e em verde, aqueles que remetem a cooperativismo, palavra que nomeia a Feira e que nos serve de aporte inicial de análise. Em azul e entre colchetes, notas do pesquisador.

\begin{tabular}{|c|c|}
\hline & $\begin{array}{l}\text { Cronologia da FEICOOP - } 1994 \text { a } 2008 \\
\text { Nomes da Feira e elementos centrais nos cartazes }\end{array}$ \\
\hline 1994 & $\begin{array}{l}1^{\text {a }} \text { Feira do Cooperativismo } \\
\text { Projetos Comunitário: Mais qualidade de vida }\end{array}$ \\
\hline 1995 & $\begin{array}{l}2^{\text {a }} \text { Feira do Cooperativismo } \\
\text { Projetos Comunitário: Mais qualidade de vida }\end{array}$ \\
\hline 1996 & $\begin{array}{l}\text { III Feira do Cooperativismo } \\
\text { Projetos Comunitário: Mais qualidade de vida }\end{array}$ \\
\hline
\end{tabular}




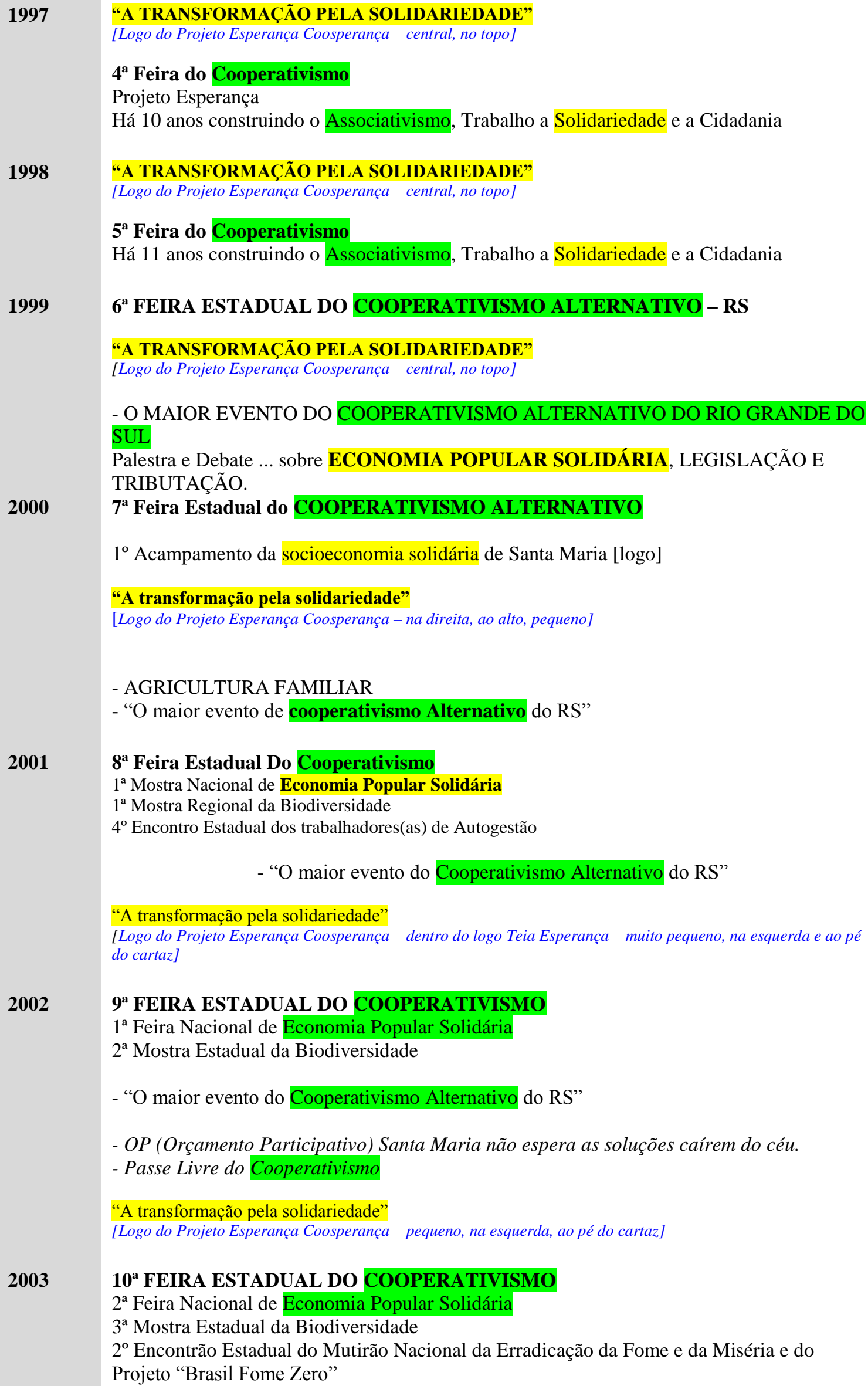


- “O MAIOR EVENTO DO COOPERATIVISMO ALTERNATIVO DO RIO GRANDE DO SUL"

- Mutirão Nacional "Fome Zero" e as Alternativas de Trabalho

- Sementes patrimônio da humanidade

"A transformação pela solidariedade"

[Logo Projeto Esperança Coosperança - dentro do logo Teia Esperança, sem o enunciado "A transformação pela solidariedade" que vinha no topo, posição central, parte de uma rede]

$2004 \quad 1^{\mathrm{a}}$ FEIRA ESTADUAL DO COOPERATIVISMO

$3^{\mathrm{a}}$ Feira Nacional de EPS (Economia Popular Solidária)

$4^{\text {a }}$ Mostra Regional da Biodiversidade

Seminário Nacional de EPS e as Políticas Públicas para o Brasil

- O MAIOR EVENTO DO COOPERATIVISMO POPULAR DO RS E DO BRASIL

\section{$12^{\mathrm{a}}$ FEICOOP}

[a partir desta ed. o logo do Projeto Esperança Cooesperança, sem o enunciado "A transformação pela solidariedade" que vinha no topo, passa a preencher o $1^{\circ}$ 'o' de Feicoop, e o logo Teia Esperança preenche o $2^{\circ}$ 'o']

Feira Estadual do Cooperativismo

$1^{a}$ FEIRA DE ECONOMIA SOLIDÁRIA DO MERCOSUL

$4^{\text {a }}$ Feira Nacional de Economia Solidária

$5^{\text {a }}$ Mostra da Biodiversidade

- UMA OUTRA ECONOMIA ACONTECE

- O Maior Evento do Cooperativismo Popular do RS e do Brasil

$2006 \quad 13^{\text {a }}$ FEICOOP

Feira Estadual do Cooperativismo

$2^{a}$ FEIRA DE ECONOMIA SOLIDÁRIA DO MERCOSUL

$5^{\text {a }}$ Feira Nacional de Economia Solidária

$6^{\text {a }}$ Mostra da Biodiversidade

- O Maior Evento do Cooperativismo Popular do RS e do Brasil - "UMA OUTRA ECONOMIA ACONTECE'

2007 O Maior Evento do Cooperativismo Popular do Brasil e do Mercosul

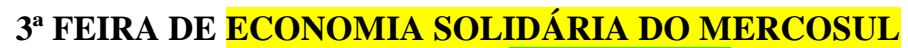

14 ${ }^{a}$ FEICOOP - Feira Estadual do Cooperativismo

$6^{a}$ Feira Nacional de Economia Solidária

$7^{\mathrm{a}}$ Mostra da Biodiversidade e Feira da Agricultura Familiar

$1^{\circ}$ Seminário Latino Americano de Economia Solidária

\section{- UM OUTRO MUNDO É POSSÍVEL - "UMA OUTRA ECONOMIA ACONTECE"}

\section{$4^{\text {a }}$ FEIRA DE ECONOMIA SOLIDÁRIA DO MERCOSUL}

15 $^{\text {a }}$ FEICOOP - Feira Estadual do Cooperativismo

$7^{\mathrm{a}}$ Feira Nacional de Economia Solidária

$8^{\text {a }}$ Mostra da Biodiversidade e Agricultura Familiar

$4^{\circ}$ Seminário Latino Americano de Economia Solidária

Mini-Fórum Social de Economia Solidária 


\section{- 15 anos-DE SANTA MARIA PARA O MUNDO}

Quadro 1 - Cronologia das Feiras e Recortes

Com base nos exemplos que recortamos das imagens para compor o quadro 1, e após a análise das imagens e enunciados nos cartazes em seu conjunto, elaboramos, os quadros 2 e 3, focando-nos nos dizeres sobre cooperativismo e solidariedade, conforme destacamos no quadro cronológico.

\section{O que desliza e o que desloca}

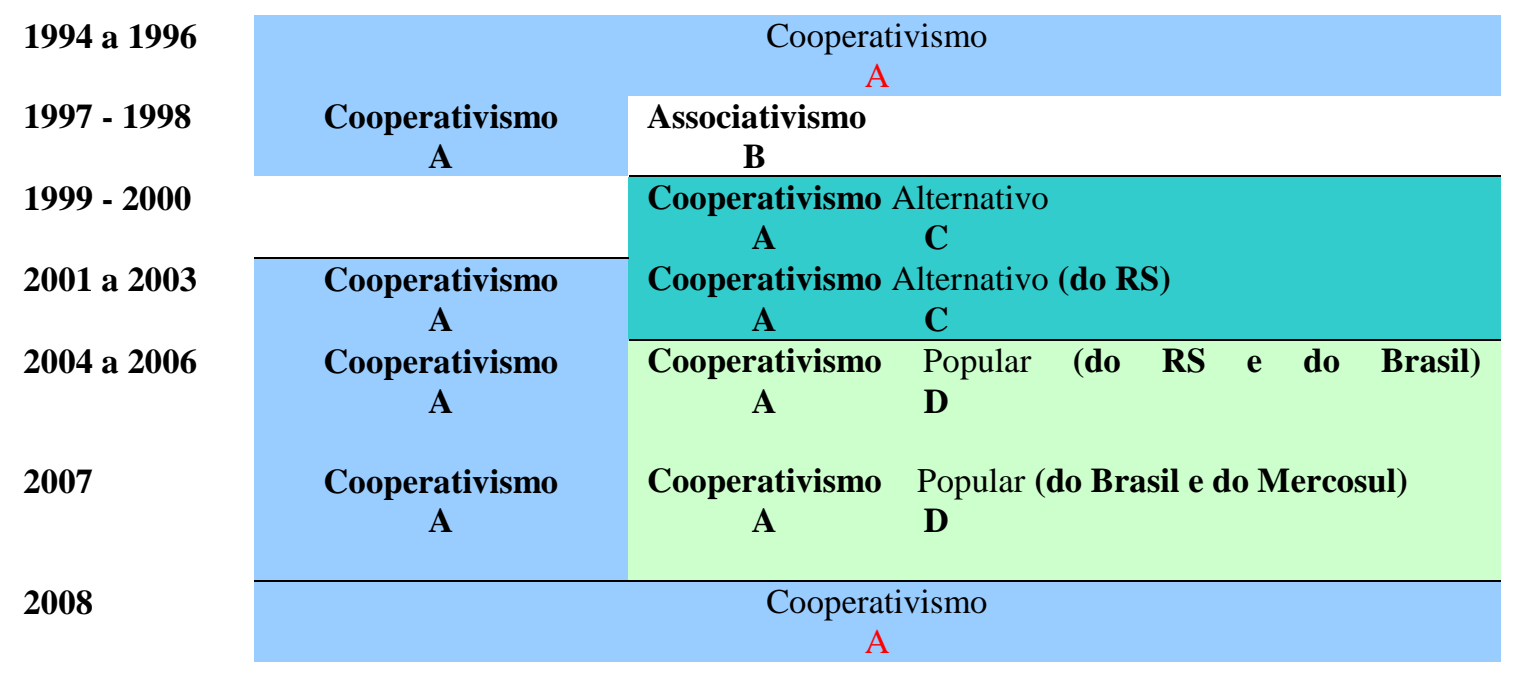

Quadro 2 - Cooperativismo

Para compreendermos os deslizamentos de sentido, ilustrados no quadro 2, podemos dizer que cooperativismo (A) está para associativismo (B), bem como para alternativo (C) e também para popular (D) que são acréscimos que fazem deslizar o sentido de cooperativismo de forma a diferenciá-lo de outras organizações socioeconômicas cooperativistas/cooperativadas com atuação semelhante às empresas de mercado, notadamente em áreas especializadas como finanças (fomento ao crédito) e médico-hospitalar (planos de saúde). Como pudemos observar no quadro 2, o cooperativismo que dá nome à Feicoop (Feira do Cooperativismo) vai sendo qualificado ano após ano em torno de uma adjetivação que o torna alternativo e popular. Os deslizamentos de sentido que se efetivam por meio dessa adjetivação somam atributos à palavra, determinando-a, especificando-a, historicizando-a, com referência aos princípios que orientam o discurso sobre a solidariedade na Feicoop. 
Acreditamos que essa diferenciação possa ser compreendida fundamentalmente pelo modo de organização no qual os integrantes provindos de uma condição de exclusão se associam a uma forma de gestão democrática e participativa que, no caso deste estudo, se oferece como alternativo ao modo capitalista.

Por sua vez, o quadro 3 visa a dar uma mostra de como se pode compreender a historicidade para solidariedade na Feicoop.

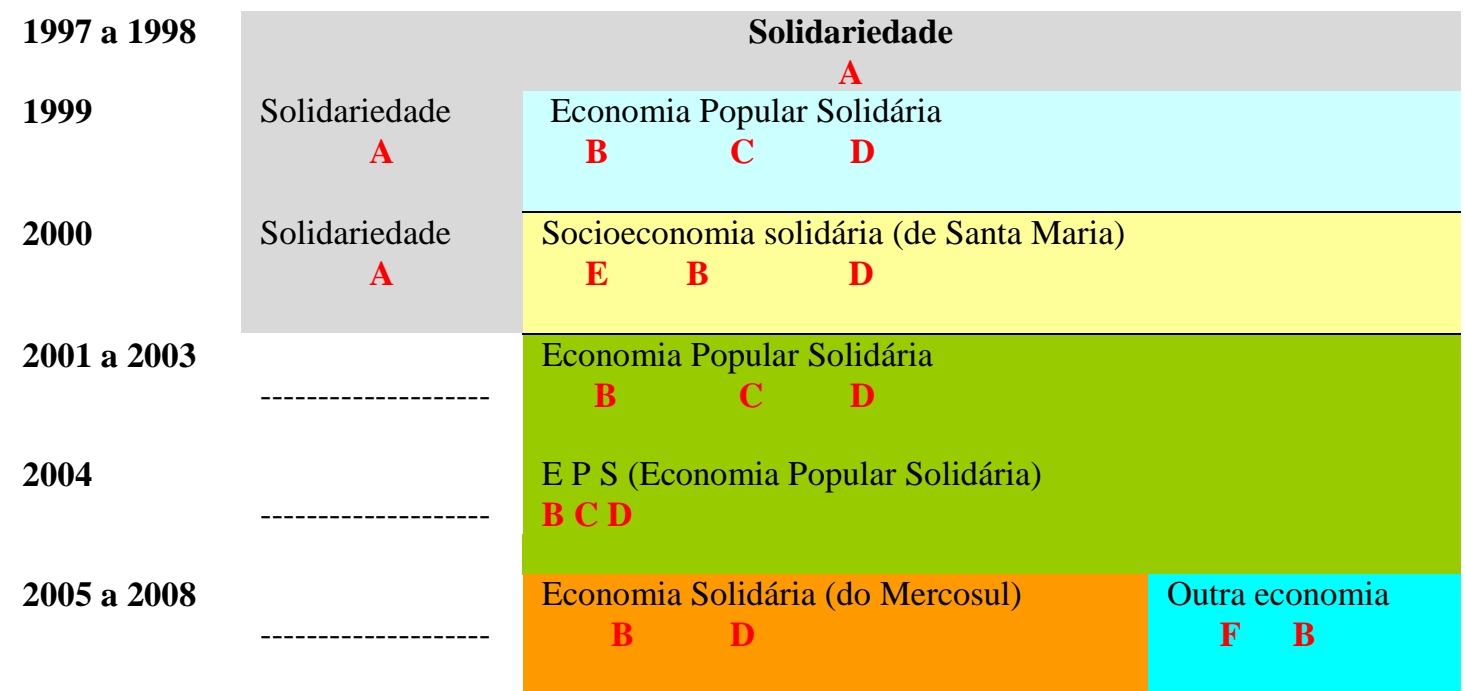

Quadro 3 - Solidariedade

O quadro 3 visa dar uma mostra de como se pode compreender a historicidade para solidariedade na Feicoop. De acordo com Orlandi, a historicidade é:

representada pelos deslizes produzidos nas relações de paráfrase que instalam o dizer na articulação de diferentes formações discursivas, submetendo-os à metáfora (transferências), aos deslocamentos: possíveis 'outros' (ORLANDI, 2003, p. 79). ${ }^{4}$

Com base na formulação da autora, que se sustenta na noção de efeito metafórico formulada por Pêcheux (1997), ou seja, fenômeno semântico produzido por uma substituição contextual, conforme já mencionamos, e no conceito de "deriva de sentidos" (PÊCHEUX, 2008) ${ }^{5}$, acreditamos ser possível enunciar que a paráfrase está para o deslize e a metáfora para o deslocamento. O que com isso queremos dizer é que há uma nuance entre deslize e deslocamento, embora tanto um quanto outro dependam das relações de paráfrase, um deslize, por exemplo, pode configurar efeitos

\footnotetext{
${ }^{4}$ Grifo no texto, negritos nossos.

5 "todo enunciado é intrinsecamente suscetível de tornar-se outro, diferente de si mesmo, ao deslocar discursivamente de seu sentido para derivar para um outro" (PÊCHEUX, 2008, p. 53).
} 
de sentido da ordem da repetição do mesmo com alguma modificação que não acarreta mudança de posição sujeito ou mesmo de FD, por exemplo, mantém-se uma certa regularidade, porém, ela é, em alguma medida, quebrada, quando há de fato um deslocamento de sentidos, quando o sentido parafraseado é metaforizado, quando ele é interpretado e dá indícios de outras relações de sentidos, "outros" sentidos.

Além disso, é interessante observar que Pêcheux (1997), em relação ao efeito metafórico e as relações de paráfrase, atenta para o risco de uma eventual "criação infinita" que levaria a dizer que toda e qualquer paráfrase seria possível por contiguidade, paralelismo, domínios semânticos, etc. $\mathrm{O}$ excesso dessas relações é regulado por uma dominância ditada pelas $\mathrm{CP}$ dos discursos, de modo que a produtividade dessas relações não é infinita e elas não podem ser quaisquer, pois estão reguladas historicamente. Assim, o fenômeno de deriva desencadeado pelo efeito metafórico está baseado "na determinação do processo discursivo pelas suas condições de produção $(\mathrm{CP})$ e na recusa da noção ideológica da criação infinita" (PÊCHEUX, 1997, p. 104).

Por conseguinte, podemos dizer que, no quadro 3 intitulado solidariedade, as relações entre $\mathbf{A}, \mathbf{B}, \mathbf{C}, \mathbf{D}, \mathbf{E}$ produzem deslizes de sentido para solidariedade, enquanto F constitui um "outro" sentido, um deslocamento de fato, na medida em que as relações de sentido que se estabelecem apontam para outras discursividades, o popular vai se articular aos discursos vinculados ao FSM, por exemplo, como dão a dimensão, as imagens seguintes:

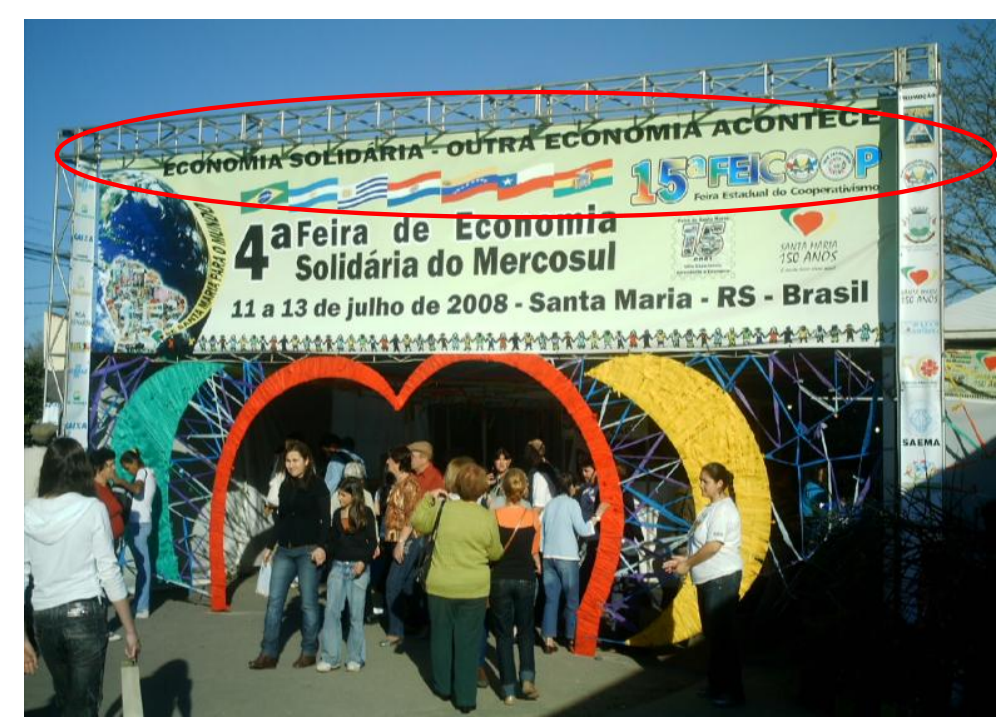

Ilustração 2 - Entrada da $15^{\text {a }}$ Feicoop, 2008.

Fonte: Acervo Pessoal. 


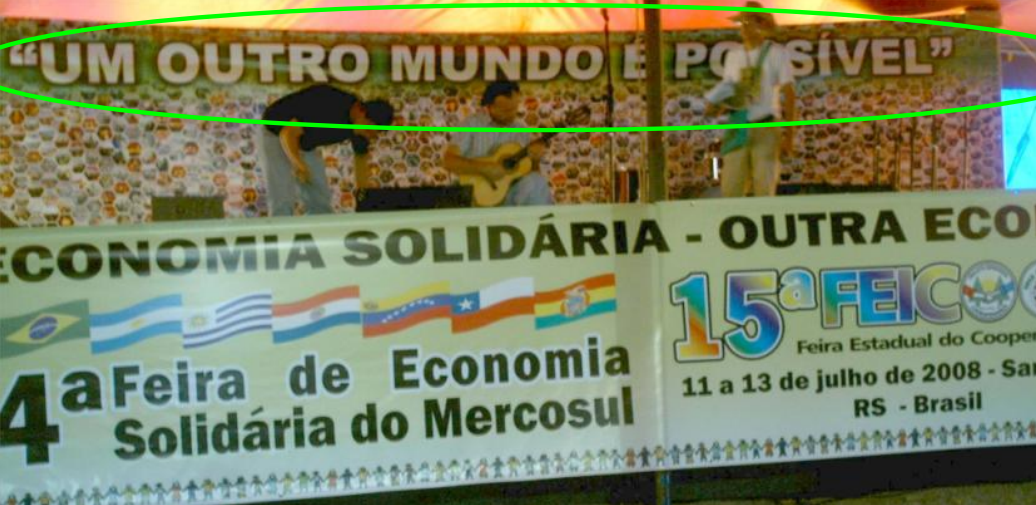

Ilustração 3 - 15 $5^{\text {a }}$ Feicoop, 2008.

Fonte: Acervo Pessoal.

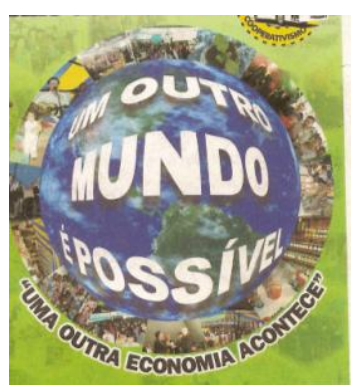

Ilustração 4 - Detalhe do cartaz da $14^{\text {a }}$ ed. da Feicoop, 2007.

Entendemos assim que, pelo jogo da paráfrase que constitui efeitos metafóricos (deslizes e/ou deslocamentos de sentido), a palavra solidariedade vem a significar uma prática social que vai resultar na acepção uma economia outra (quadro 3 Solidariedade): esse seria propriamente o deslocamento, uma vez que solidariedade, por sucessivos efeitos metafóricos (deslizes de sentido), faz acontecer uma outra economia (a EPS). Além disso, acreditamos ser possível dizer que há um deslocamento significativo nos sentidos de solidariedade ao longo de 15 anos.

\section{Um discurso sobre a solidariedade}

Ao considerarmos, inicialmente, os enunciados dos cartazes em ordem cronológica, podemos dizer que eles vão constituindo pela deriva de sentidos um lugar para o discurso sobre a solidariedade na Feicoop. Como sabemos, o funcionamento da ideologia se dá pelo excesso, saturação e não pela falta (cf. Orlandi, 2007, p. 66). Por outro lado, as repetibilidades vão se deslocando, segundo o jogo linguístico que projeta os sentidos, os sujeitos, a um "outro lugar", "um projeto" a ser alcançado.

Na esteira de Orlandi (1990), consideramos que o discurso sobre solidariedade, na relação com os saberes do discurso de que lhe constitui, é organizado sob a forma de repetições e reformulações, doutrinamentos, veiculados, muitas vezes, por um portavoz, voz de autoridade que produz certo efeito de homogeneidade em relação às vozes heterogêneas e dispersas do "discurso de".

O discurso sobre é uma das formas decisivas de institucionalização dos sentidos, uma vez que engendra uma espécie de mecanismo controlador dos dizeres [do discurso 
de] que constituem uma memória dispersa e muitas vezes dissonante de um sentido que se quer dominante.

Em relação aos saberes que constituem o discurso da solidariedade que circula na Feicoop, no que concerne às bases que fundam esse discurso (essa prática), podemos dizer que este se trata de um discurso que inicialmente pode ser vinculado àquele de pequenos produtores rurais e urbanos, entre os quais se encontra o colono, (este que, entre outros, é um dos personagens centrais na fundação da Cooperativa Esperança e que desde então faz funcionar semanalmente um local de comercialização desses produtos denominado Feirão Colonial). Também podem ser inseridos na formulação do discurso "de", no espaço discursivo da Feicoop: produtores na agricultura familiar (urbanos e rurais), artesãos e recicladores (conforme círculo inferior direito, na ilustração 5, abaixo). Entretanto, esse mesmo espaço discursivo se constitui na relação com outras instâncias apoiadoras e/ou organizadoras das ações e dos discursos (EMATER, Banco do Povo, PRONAF, Prefeitura Municipal de Santa Maria, CÁRITAS, UFSM, etc.). É importante salientar que a organização desse discurso sobre solidariedade se dá na complexificação e instalação de diferentes demandas, aquelas do sujeito urbano que vai se inserindo nessa prática/discurso (em relação aos saberes/demandas inicialmente vinculadas ao pequeno produtor rural).

A ilustração 5 é representativa da organização do Projeto Esperança/Cooesperança e a nomeamos de diagrama do discurso de/sobre solidariedade. 


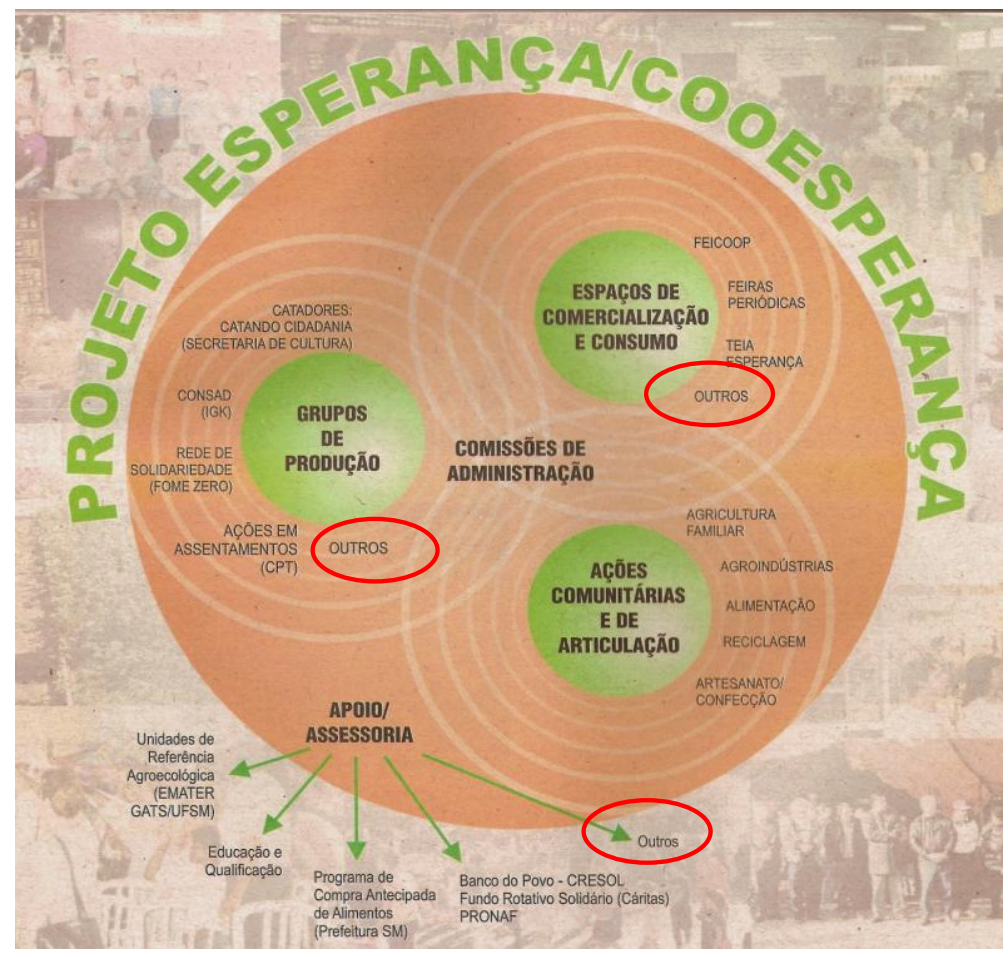

Ilustração 5 - Instâncias da organização do Projeto Esperança/Cooesperança.

Fonte: SARRIA ICAZA; FREITAS, 2006, p. 70.

A ilustração 5 traz uma representação gráfica de um grande círculo nomeado como Projeto Esperança/Cooesperança, no interior do qual há três círculos que se expandem também por meio de círculos que se sobrepõem (entrecruzam). Os três círculos são nomeados respectivamente como Grupos de produção; Espaços de comercialização e consumo e Ações comunitárias e de articulação. Nos lugares intermediários, entre os três círculos, situamos o espaço de circulação/constituição/formulação do discurso da solidariedade na Feicoop, uma vez que a representação nos oferece uma dimensão possível dos movimentos e da heterogeneidade constitutiva do discurso "de" na relação com o discurso "sobre", marcando o imbricamento entre ambos.

Os sentidos para solidariedade (no imbricamento entre discurso de e sobre) se constituem, contraditoriamente, talvez, como ressonância de demandas, de urgências que são da ordem/contraordem do cenário de mundialização. $\mathrm{O}$ social (dispersão, divisão) é sobredeterminado pelo solidário, e este pelo que seja produtivo, cidadão, associativo. E, nesse modo de significar, o real de um saber prático, oriundo da experiência do trabalhador rural, do colono, é substituído por categorias, elementos, discursos do urbano em torno da organização política, administrativa, jurídica e 
comercial (no caso, do processo de comercialização direta aos consumidores). Podemos então dizer: organizam-se sentidos na ordem do discurso "sobre", o que acarreta um efeito de homogeneização. Contudo, no discurso "sobre", o discurso "de" deixa seus vestígios, como marca dos sujeitos que o fazem funcionar, que o praticam.

Como observamos, há diferentes instâncias de constituição/formulação/circulação (e organização) do discurso sobre (e de) solidariedade na Feicoop e vale destacar que os "outros" também estão presentes [vide destaques vermelhos na imagem].

\section{Conclusão}

Este estudo nos possibilitou a experimentação de que há o mesmo no diferente, há um imbricamento entre eles, ditado pelos processos históricos do dizer, os quais foram trazidos à tona por meio da produtividade analítica da noção de efeito metafórico que proporcionou a desconstrução de efeitos de evidência.

Analisamos a discursivização da palavra solidariedade que constitui um discurso que conclama a um fazer ético, via práticas produtivas e subjetivas de forma a instaurar uma "outra" economia - contrária a que circula sob a égide dos mercados globais, sendo reproduzida pela ideologia do capitalismo neoliberal.

Compreendemos que o discurso sobre a solidariedade na Feicoop, guarda relação com o "discurso de", sem apagá-lo e preconiza a construção de uma sociedade socialmente justa, economicamente viável, ambientalmente sadia, organizadamente solidária e cooperativada, politicamente democrática, por meio de "outro" modelo de desenvolvimento. Nesse sentido, os enunciados "Uma outra economia acontece" e um “Outro mundo é possível” referenciam uma oposição e não uma destituição ou substituição do capitalismo e instauram uma prática que torna possível o "outro", mediante uma economia popular solidária.

Essas relações de sentido, à luz da $\mathrm{AD}$, permitiram-nos considerar que o dizer é polissêmico, pois não encontra um "sentido próprio" do qual "desvia", observa-se que, resguardadas sempre as condições de produção de um discurso, ele se determina historicamente, de forma que não pode ser "qualquer um". Nesse caso, a economia determinante na Feicoop é "outra" (não a dominante) e é "solidária" (e não capitalista). As determinações recobrem essa discursividade e, em nossa compreensão, dão força a esse discurso. Elas formulam as oposições. Em um cenário hodierno de fluidez e 
competição, marca-se a "diferença" necessária. O sentido não é qualquer um, e em um processo (discursivo ou econômico) de circulação em massa, diferente e mesmo, diametralmente opostos, revezam-se em um jogo (político e linguístico).

Para nós, o discurso sobre solidariedade efetua-se na dimensão de linguagem proposta por Orlandi (2006, 2003), na medida em que, por meio das relações de paráfrase e, considerada a polissemia constitutiva do processo de produção de linguagem, realiza-se a metáfora do outro mundo/outra economia, lugar da expressão de luta e de discursos que se afirmam como diferentes. O que nos conduz à conclusão de que a "outra economia" se constitui via um efeito metafórico que faz deslocar o discurso sobre solidariedade do âmbito social para o econômico e, pela linguagem, põe em funcionamento uma prática discursiva traduzida no discurso econômico-social.

Assim, entendemos que há uma complexa e distinta afinidade nas relações entre os que atuam sob um fazer capitalista (lideram processos e modos de desenvolvimento econômico no âmbito da globalização) e os que encetam iniciativas econômico-sociais alternativas a partir de práticas solidárias. Eles compartilham, em parte, os mesmos valores fundamentais, há o mesmo no(s) diferente(s). O que os divide são os interesses sociais que os motivam precipuamente, o que influi na discursivização que empreendem e permite a análise desse funcionamento discursivo no tocante ao que deriva.

\section{Referências Bibliográficas}

ORLANDI, Eni P. Interpretação. Autoria, leitura e efeitos do trabalho simbólico. Campinas, SP: Pontes. 2007. 5. ed.

A linguagem e seu funcionamento: as formas do discurso. Campinas, SP: Pontes. 2006. 4. ed.

Análise de discurso. In: ; LAGAZZI-RODRIGUES, Suzy (Orgs.).

Discurso e textualidade. Campinas, SP: Pontes. 2006a. 5. ed. Análise de discurso. Princípios e procedimentos. Campinas, SP: Pontes. 2003.

Terra à vista. Discurso do confronto: Velho e novo mundo. São Paulo: Cortez/ Campinas, SP: Editora da Unicamp. 1990.

PÊCHEUX, Michel. O discurso. Estrutura ou acontecimento. Traduzido por Eni P. Orlandi. Campinas, SP: Pontes. 2008. 5 ed. Análise Automática do Discurso (AAD-69). Traduzido por Eni P. Orlandi. In: HAK, Tony; GADET, Françoise (Orgs.) Por uma análise automática do discurso: Uma introdução à obra de Michel Pêcheux.Traduzido por Bethania S. Mariani [et al.] 3. ed. Campinas, SP: Editora da Unicamp. 1997. 
REVISTA DO HISTÓRICO DOS 15 ANOS DA FEIRA DE SANTA MARIA: Uma experiência aprendente e ensinante. Projeto Esperança/Cooesperança. Santa Maria, RS: Diocese de Santa Maria e Apoiadores. 2008. 
Para citar essa obra:

VARGAS, André Luís Campos. Derivas de sentido no discurso sobre a solidariedade na Feicoop. RUA [online]. 2012, no. 18. Volume 1 - ISSN 1413-2109

Consultada no Portal Labeurb - Revista do Laboratório de Estudos Urbanos do Núcleo de Desenvolvimento da Criatividade

http://www.labeurb.unicamp.br/rua/

\section{Laboratório de Estudos Urbanos - LABEURB}

Núcleo de Desenvolvimento da Criatividade - NUDECRI

Universidade Estadual de Campinas - UNICAMP

http://www.labeurb.unicamp.br/

Endereço:

Rua Caio Graco Prado, 70

Cidade Universitária “Zeferino Vaz" - Barão Geraldo

13083-892 - Campinas-SP - Brasil

Telefone/Fax: (+55 19) 3521-7900

Contato: http://www.labeurb.unicamp.br/contato 